\title{
Etologia humana: o exemplo do apego
}

\author{
Plínio Marco De Toni \\ Caroline Guisantes De Salvo \\ Marcos César Marins \\ Lidia Natalia Dobrianskeyj Weber ${ }^{1}$
}

\begin{abstract}
Resumo
O objetivo deste estudo é apresentar, de maneira didática, a perspectiva evolucionária no estudo do comportamento humano. Para isso, apresenta-se a etologia, apontando algumas variações nas perspectivas de estudo da área. A etologia surgiu com o objetivo de estudar os comportamentos inatos nas diversas espécies em ambiente natural. Atualmente pode-se falar em duas tendências: a etologia tradicional e a ecologia comportamental, preocupadas, respectivamente, com as causas imediatas e evolutivas do comportamento. Superando concepções dualistas como inato-aprendido e natureza-cultura, a etologia tem contribuído para a compreensão do comportamento humano. Neste artigo, apresenta-se como exemplo o desenvolvimento do apego, relacionando pressões seletivas, neotenia, cuidados parentais e o surgimento da instituição familiar.

Palavras-Chave: Etologia humana; Ecologia comportamental; Teoria do apego.
\end{abstract}

\section{Human ethology: The attachment example}

\begin{abstract}
The purpose of this paper is to present, in a didactic manner an evolutionary perspective concerning the study of human behavior. In order to do this, an ethological perspective is given, indicating a number of variations in the study of the subject. Ethology first arose as the scientific study of innate behavior of different species that occurs in a natural environment. Currently we consider that there are two tendencies: a traditional ethology and a behavior ecology addressing immediate and evolutionary causes of behavior, respectively. Beyond the dualist concepts, innate-learned and nature-culture, ethology has contributed to the understanding of human behavior. In this paper, we have included the examples of the development of attachment and its relation with selective pressures, neoteny, parental care and the emergence of the family institution.

Keywords: Human ethology; Behavioral ecology; Attachment theory.
\end{abstract}

A teoria evolutiva é uma das perspectivas que traz grandes contribuições para o estudo do comportamento. Desde que o livro A origem das espécies, de Charles Darwin, foi publicado, com sua primeira edição em 1859 (Darwin, 2000), diversas ciências surgiram com o objetivo de estudar os mecanismos do comportamento através de um prisma evolucionário. De acordo com Alcock (2003), foram Konrad Lorenz e Niko Tinbergen que, em meados do século XX, fundaram a abordagem biológica moderna para estudo do comportamento. Ao contrário da perspectiva evolucionária na psicologia caracterizada pelo behaviorismo americano (Bateson, 2003), que realizava estudos em laboratório com poucas espécies animais, Shettleworth (2001) afirma que a etologia surgiu na Europa com o objetivo de estudar os comportamentos inatos nas diversas espécies em ambiente natural.

Nesse sentido, Tinbergen (1951) postulou que haveria quatro questões principais que norteariam as pesquisas em comportamento animal: quais são as causas imediatas de um determinado comportamento (causalidade); como ele se desenvolve durante a vida do indivíduo (ontogênese); qual a sua função (valor de sobrevivência); como ele se desenvolveu durante a evolução (filogênese). Desde então, o aprimoramento metodológico, uma maior compreensão da história natural das espécies e a interface com outras ciências permitiram transformações no campo de estudo do comportamento animal (Altmann \& Altmann, 2003). Alcock (2003) faz uma descrição interessante do desenvolvimento das ciências do comportamento animal, numa perspectiva histórica. Segundo ele, de 1950 a 1975, a grande maioria dos livros e artigos científicos da área foram sobre os mecanismos causais imediatos e a ontogênese do comportamento. A esta abordagem denominou-se etologia tradicional, preocupada essencialmente com as duas primeiras questões de Tinbergen: as causas próximas. A partir de 1975, emerge uma outra ciência denominada

${ }^{1}$ Endereço para correspondência:

UFPR - Departamento de Psicologia - Praça Santos Andrade, 50/1o andar - Curitiba-PR - 80060-000

E-mail: lidia@ufpr.br 
ecologia comportamental. Como a etologia tradicional, o seu objeto de estudo é o comportamento das espécies. No entanto, a ecologia comportamental preocupa-se em responder as questões acerca da evolução filogenética e do valor de sobrevivência do comportamento para a espécie. Focaliza, neste sentido, as duas últimas questões de Tinbergen, contextualizando os comportamentos de uma espécie na história evolutiva e correlacionando-os com aspectos ecológicos (Krebs \& Davies, 1996). De acordo com West, King e White (2003), atualmente esta abordagem é a dominante nas pesquisas sobre comportamento animal.

O enfoque biológico no estudo do comportamento supera concepções dualistas traduzidas pelas dicotomias inato-aprendido, organismo-ambiente e natureza-cultura (Blurton Jones, 1981). Como afirma Carvalho (1989),

\section{o enfoque etológico não se caracteriza como um enfoque inatista, mas sim como um enfoque interacionista, no qual é central um conceito de ambiente específico da espécie. (p. 85)}

No caso do homem, este ambiente é marcado fortemente pela cultura que, de forma alguma, pode ser desvinculada da evolução biológica. De fato, no gênero Homo "a cultura produziu o cérebro que a produz" ( $\mathrm{p}$. 89). Nesse sentido, o objetivo deste artigo é apresentar, de forma introdutória, uma síntese descritiva do campo de estudo da etologia humana, enfocando o desenvolvimento do apego e suas relações com pressões seletivas, neotenia, cuidados parentais e o surgimento da instituição familiar.

\section{Sobre Evolução Humana}

Há 10 milhões de anos (período quaternário da era cenozóica) iniciou-se uma era de mudanças ambientais, associada a um processo de evolução por seleção natural, que culminou nas adaptações hominídeas conhecidas pelo termo hominização. De acordo com Sanvito (1991),

\section{por hominização entende-se o processo através do qual os nossos antepassados pré-bominídeos, que nos são comuns com os antropóides, adquiriram características anatômicas e fisiológicas próprias dos hominídeos até chegar ao Homo sapiens. (p. 8)}

De forma dialética, alterações ambientais e hominização interagiram, originando as formas mais complexas de comportamento.

Os fatores ambientais relacionadas ao surgimento do gênero Homo estão associados a modificações geológicas. O choque de placas tectônicas no continente africano influenciou no relevo da região, modificando o fluxo de ventos e, conseqüentemente, a transposição de nuvens de chuva da costa oeste africana para as florestas tropicais (Leakey, 1997; Lewin, 1999). O resultado foi uma escassez de chuva, promovendo a transformação das florestas africanas em savanas há aproximadamente 12 milhões de anos. Diversas espécies de primatas que lá habitavam sucumbiram. No entanto, foi provavelmente neste cenário que o gênero Australopithecus sobressaiu-se, fazendo com que uma região específica do leste da África fosse a origem do Homo sapiens, com a primeira espécie bípede. Além disso, não somente a primeira espécie bípede, mas o próprio Homo sapiens sapiens teria origem africana, como afirma o modelo "saída da África", em contraposição à hipótese multiregional (Stringer, 2003).

Com as novas condições ambientais, uma forma mais eficiente de locomoção foi selecionada: a marcha bípede. Diversas hipóteses que relacionam a vida nas savanas com o bipedismo foram propostas (Leakey, 1997). Entre elas: a necessidade de ter um campo de visão maior para controle dos predadores; a liberação dos membros anteriores para a coleta e transposição de alimentos; o uso de instrumentos; a adoção de uma postura mais eficiente para evitar ao máximo a incidência de raios solares. No entanto, a hipótese mais aceita atualmente é a da "eficiência energética", afirmando que a marcha bípede é um modo de locomoção mais eficiente (em termos energéticos) que o quadrupedismo simiesco (Leakey, 1997; Lewin, 1999).

Este fato marca a transposição de modos de vida distintos. Da vida arborial para as savanas, as adaptações que se deram influenciaram diretamente a locomoção e, com isto, a função dos membros anteriores e posteriores. Os pés passaram da preensão arborial para a locomoção térrea (braquiação para bipedismo) e, assim, as mãos tornaram-se livres para uma preensão práxica. Já nos primatas arborícolas, a redução do olfato proporcionou a diminuição da face, verticalizando o osso frontal e, conseqüentemente, desenvolvendo as funções de planejamento próprias desta região cerebral. Além disso, a agilidade motriz necessária para a locomoção nas árvores esteve associada à aquisição de melhores habilidades viso-motoras (Sanvito, 1991).

Quanto às alterações anatômicas que possibilitaram o bipedismo, cabe ressaltar as principais: redução da pélvis e do tórax, transferindo o centro de gravidade para trás; alteração da posição do forâmen magno, liberando o osso occipital da pressão da coluna vertebral; diminuição do peso dos ossos; redução no tamanho dos membros superiores; movimentação da cintura escapular para a região dorsal, dando maior flexibilidade aos membros superiores. Estes fatores, juntamente com a redução gradual da mandíbula (devido à dieta omnívora e ao uso do fogo para cozimento alimentar), proporcionaram a verticalização do osso frontal, o enrolamento do occipital e o alargamento do parietal. Desta forma, o desenvolvimento das 
respectivas áreas cerebrais foi possível (Fonseca, 1998).

A liberação das mãos da função locomotora proporcionou a praxia fina, com a mobilidade da escápula, aliada aos movimentos de supinação e pronação (rádio e ulna) e, principalmente, a oponibilidade do polegar. Como afirma Fonseca (1998), “a preensão no homem... não serve para sustentações nas árvores, mas sim para a função de manipulação de objetos e para a fabricação de instrumentos" (p. 58). Estes novos fins para a função preênsil tiveram correspondências cerebrais delineadas. Com o uso progressivo das mãos para atividades que necessitavam praxia fina, as regiões corticais responsáveis pela sensibilidade tátil se desenvolveram. Em suma, o que se tem é uma maior projeção das mãos (e, principalmente, dos polegares) nas áreas parietais e frontais correspondentes, respectivamente, aos bonecos de Penfield sensitivo e motor. Para se compreender a importância que os membros superiores (e, em especial, a mão) adquiriram para a espécie humana, basta considerar que a representação do polegar no córtex, demonstrado pelo homúnculo de Penfield, "é absurdamente grande, enquanto que tronco, braços e pernas são pequenos" (Bear, Connors \& Paradiso, 2002, p. 414).

\section{Pressões seletivas e o desenvolvimento do apego}

Fatores fundamentais para a compreensão do desenvolvimento do afeto no gênero Homo são as modificações que ocorreram do ponto de vista da reprodução humana, conseqüentes das transformações que a marcha bípede trouxeram.

Com a bipedismo e a posição ereta do corpo, as modificações anatômicas na pélvis são significativas, pois é necessária a redução de sua estrutura para possibilitar a marcha. Dentre as conseqüências do andar bípede (neste caso devido à redução da pélvis) está a gestação humana. Por um processo de seleção natural, filhotes nascidos prematuramente tinham probabilidade maior de sobrevivência. $O$ neonato com mais idade gestacional (e, desta forma, de tamanho superior) simplesmente não conseguiria traspassar a barreira anatômica da bacia materna e, conseqüentemente, tanto mãe quanto filhote morreriam (Bussab \& Otta, 1992). De acordo com Leakey (1997), em comparação com os demais primatas, "o período de gestação do Homo sapiens, cuja capacidade cerebral média é de $1.350 \mathrm{~cm}^{3}$, deveria ser de 21 meses e não de 9 meses como na verdade o é" (p. 53). Esta diferença de um ano no desenvolvimento torna o recém-nascido humano frágil comparado com neonatos de outras espécies, mesmo os demais primatas. Como salienta Silk (1999), em virtude da fragilidade ao nascer, os mamíferos necessitam de cuidados e proteção contra predadores por um período mais longo. No caso da espécie humana, tal fragilidade exige cuidados parentais ainda mais prolongados, e tanto o nascimento do apego quanto o desenvolvimento da instituição familiar têm suas origens neste artifício da natureza. Por uma questão de sobrevivência, maior investimento parental foi exigido e, ao contrário de muitas outras espécies, a presença fundamental do macho reprodutor (Eibl-Eibesfeldt, 1989; Hrdy, 2001; Rodrigues, 1998; Small, 1999).

Mas é de se esperar que isto não fosse fácil num ambiente hostil como eram as savanas africanas. Então, mais uma vez os processos de seleção natural voltam a agir. Para garantir os cuidados da mãe, e sua conseqüente sobrevivência, os bebês passam a apresentar mais persistentemente, durante o curso de sua infância até mais ou menos o início da vida adulta, formas características do início de seu desenvolvimento. Isto é conhecido por neotenia (Bussab \& Otta, 1992). Essa foi uma das formas que a natureza encontrou para manter as mães mais próximas de seus filhotes por períodos maiores, garantindo sua sobrevivência por uma atração inata para essas características (Hrdy, 2001). Considerando que nos primatas a reprodução se caracteriza por nascimentos de poucos filhotes e grande investimento parental e/ou grupal em cada filhote (Rodrigues, 1998), o sucesso de nossa espécie só foi possível pela evolução de padrões comportamentais maternos e/ou paternos compatíveis com o aumento da demanda de cuidados da prole.

Como afirmam Cunningham e Birkhead (1998), o sucesso evolutivo de um indivíduo não depende somente de suas habilidades de sobrevivência ou reprodução, mas também da produção de descendentes que cheguem à vida adulta e se reproduzam. No caso do gênero Homo, como geralmente nascia apenas um filhote por prole, o investimento parental se tornava fundamental para o sucesso da espécie. E como então surgiu o investimento paterno nos cuidados da prole? Um dos fatores que pode estar relacionado é a perda dos indicadores de cio na fêmea (Rodrígues-Gironés \& Enquist, 2001). Assim, para que um macho tivesse garantias de paternidade, e então fosse vantajoso cuidar do filhote como um meio de perpetuar seus genes, era necessário que estivesse sempre perto da fêmea para garantir que nenhum outro copulasse com ela, e ele não cuidasse do filhote de outro. Mas isto não aconteceu de uma forma tão simples. Era necessário que o macho não soubesse quando do período fértil da fêmea e assim se mantivesse sempre perto dela. Desta forma, por seleção natural a fêmea foi perdendo as características que indicavam seu período fértil, como o inchaço nos lábios vaginais e o cheiro característico pela liberação de hormônios que atraía o macho para a cópula. Com isto a fêmea estava sempre pronta para a atividade sexual, garantindo a presença do macho e sua ajuda no cuidado dos filhotes. Além disso, como em diversas espécies 
monogâmicas (Rodrígues-Gironés \& Enquist, 2001), uma receptividade sexual permanente por parte da fêmea (e não somente durante o período fértil) favorece a permanência do macho, já que este tem menos informações sobre períodos reprodutivos. Mesmo assim, dentre os mamíferos, a espécie humana é uma das poucas espécies em que o macho apresenta investimento parental direto na prole (Bjorklund e Pellegrini, 2002). Todo este processo foi uma relação dialética e multideterminada, chegando ao que hoje se denomina de padrões reprodutivos da espécie humana.

Por parte do filhote, o desenvolvimento da neotenia facilitou o envolvimento dos adultos nos cuidados parentais e, em muitos casos, aloparentais (Silk, 1999). Segundo Bussab e Otta (1992), o rosto do bebê tem características que são sinais poderosos para provocar sentimentos ternos e protetores, quando comparados ao padrão facial adulto: rosto arredondado, olhos maiores, testa abobadada, nariz menor, bochechas redondas e queixo recuado. Existem também outros sinais que se somam às características anatômicas, como o choro, o olhar fixo e o sorriso, fatores que facilitam a proximidade e deixam o "bebê adorável" (Hrdy, 2001). Além disso, por este contato entre pais e bebê facilitado pela neotenia, nota-se uma predisposição do filhote Homo sapiens para a vida social. Além disso, o leite pobre da fêmea humana e a constante necessidade de amamentação do filhote obrigam o contato mãe-bebê, reforçando ainda mais o caráter social desta relação (Rodrigues, 1998). Segundo Bussab e Ribeiro (1998), todas as relações evolutivas têm estrita relação com o contexto cultural, pois ao mesmo tempo em que foram por ele selecionadas, também propiciaram a evolução cultural. Assim, para entender a evolução do investimento parental é necessário não perder de vista que todas as alterações evolucionárias no homem estavam sempre ligadas à vida social e cultural onde ele estava inserido.

Segundo Eibl-Eibesfeldt (1989), a evolução do cuidado parental é o evento-chave que possibilitou o desenvolvimento da sociabilidade dos vertebrados, uma vez que o aparecimento dos sinais envolvidos na relação pais-filhos criou condições para o desenvolvimento das relações amigáveis e afetivas dos adultos, como afirma Miller (2001), "os pais modernos formam fortes laços emocionais com seus filhos, e esta propensão provavelmente é fruto da evolução" (p. 210). O amor parental é influenciado por vários indicadores provenientes dos pais, dos filhos e da situação, como o grau de certeza do parentesco genético pai-filho, certos atributos fenotípicos da criança, indicadores situacionais da aptidão da criança, das alternativas reprodutivas da mãe e oportunidades de investimento do pai e da mãe. Nota-se, portanto, que há vários determinantes biológicos e culturais para $\mathrm{O}$ investimento parental.

Até agora, explicitaram-se apenas os aspectos evolutivos e parentais da relação pais-filhotes. No entanto, o bebê, de maneira alguma, é um ser passivo. É importante salientar que, enquanto um comportamento modifica o ambiente, este ambiente modifica o comportamento. Assim, quando a mãe age sobre o bebê, modifica-o, e, conseqüentemente, o bebê agirá sobre a mãe, também modificando-a, e será nessas constantes relações que se dará o envolvimento afetivo.

Se o bebê não é passivo, quais seriam os determinantes biológicos e sociais com os quais ele estaria contribuindo para esta relação?

Já foi dito que o bebê apresenta certas características que servem como discriminantes para a mãe, trazendo-a para perto. Mas quais seriam os determinantes do apego? Apesar de algumas teorias acreditarem que o amor entre mãe e filhote surge de uma satisfação da alimentação ou do alívio do desconforto (Weber, no prelo), estudos etológicos mostram que isto não é verdadeiro. A teoria do impulso secundário (de âmbito psicanalítico) foi questionada, e posteriormente desacreditada, graças aos trabalhos de Lorenz sobre estampagem (Manning, 1977). O que ele provou é que o comportamento de apego pode desenvolver-se sem que tenha havido alimentação ou qualquer outra recompensa adicional por parte da figura de apego. Lorenz mostrou que nas horas seguintes após a eclosão dos ovos, patos e gansos tendem a seguir qualquer objeto que vejam em movimento, e que após certo período passam a preferi-lo a qualquer outro e a seguir somente ele. Os dados de Lorenz foram replicados e constatou-se que isto acontece também nos mamíferos de modo comparável (Bowlby, 1990).

Experimentos com macacos rhesus, feitos por Harry Harlow na década de 50, mostraram que o apego não surgia por causa das satisfações alimentares (num modelo de macaco confeccionado com arame), mas sim em razão do aconchego que eles encontravam num modelo de tecido (Harlow, 1959). Quando esses macacos (criados por modelos de arame e/ou pano) eram colocados em contato com outros animais da mesma espécie, mostravam-se socialmente inaptos. Assim, Harlow concluiu que o vínculo mãe-filhote é essencial para a saúde mental e para o desenvolvimento normal em primatas, pois é com base nesse vínculo inicial que todos os outros laços afetivos são construídos.

Foi Bowlby (1969) que denominou o vínculo mãe-filho de apego (Weber, no prelo). Para ele, o comportamento de apego mãe-bebê teria surgido para garantir proximidade segura entre adulto e bebê e é provocado pelo bebê desde seus gestos iniciais (Gross, 2002). É importante deixar claro que a vinculação afetiva não é somente o resultado automático da fisiologia, pois somos seres biologicamente culturais (Bussab \& Ribeiro, 1998). Como já foi dito, o apego garante a proteção do bebê, mas é a interação entre mãe e filho que garante a 
construção do vínculo afetivo.

Segundo Bussab e Ribeiro (1998), investigações minuciosas do comportamento de crianças pequenas têm revelado a presença de adaptações naturais para a interação social e para a formação de vinculações afetivas. Em primeiro lugar, chama a atenção a capacidade de responder preferencialmente a sinais de contato afetuoso do adulto, respondendo com abertura dos olhos e atenção à fala afetuosa de outro ser humano. Há, com o passar dos meses, um processo de estampagem da criança em relação à sua mãe (ou cuidador). Nas primeiras semanas de vida o bebê reconhece a voz e o odor da mãe; com alguns meses já discrimina sua face e passa a preferi-la a qualquer outro ser humano. Embora com 8 meses tendam a aparecer as reações mais típicas de apego à mãe e medo a estranhos, às vezes observa-se isso muito antes, com as crianças reagindo com medo a estranhos e mantendo a mãe como base de segurança (Bowlby, 1990).

O apego está intimamente ligado ao investimento parental, e dele não pode ser dissociado, pois é a partir dos sinais emitidos pelo bebê e da resposta dos pais a ele que se forma o vínculo. Não se pode pensar um sem o outro. Como mostrado no exemplo acima, de medo de estranhos, nota-se que o bebê age sobre o adulto e este responde ao bebê de uma forma que vai aumentando a vinculação afetiva pelas constantes respostas, pois, segundo Bowlby (1990), um dos fatores determinantes para o surgimento e manutenção do comportamento de apego é a rapidez com que o adulto responde ao bebê e a intensidade da interação.

O comportamento de apego, além da função de proteção, propicia ao bebê uma série de interações sociais que colaboram para um desenvolvimento saudável da criança, além de lhe proporcionar oportunidades de treinar seus comportamentos sociais e perceber as modificações dele no meio. Assim, é graças a esta proximidade mãebebê que este terá oportunidades de ver e explorar o mundo de uma maneira segura, e assim desenvolver seu cérebro, aprender com os outros de sua espécie e sentirse parte dela e seguro nela a partir do amor de seus pais. Quanto mais forte o vínculo inicial mãe-bebê, maior a probabilidade de a criança tornar-se independente no futuro, pois é o apego seguro que permite a criança aventurar-se de maneira confiante no mundo.

Segundo Weber (no prelo) a neotenia dos filhotes e sua dependência dos adultos poderia ser considerada uma desvantagem para a sobrevivência da espécie. No entanto, foi o que permitiu uma variedade de formas de desenvolvimento e educação. Foi o comportamento afetivo dos adultos (investimento parental) dirigidos a seus filhotes que possibilitou o desenvolvimento do afeto, da amizade e da própria sociedade, como afirma Bussab (2000): “...evoluímos em um contexto de vínculos afetivos individualizados - amor" (p. 19). Foi esta contínua interação entre o apego e o investimento parental que deu origem ao amor entre pais e filhos.

\section{Considerações Finais}

Este artigo teve por objetivo descrever, de forma introdutória, a perspectiva evolucionista no estudo do comportamento humano. Para tanto, apresentou aspectos gerais da evolução humana e suas relações com o desenvolvimento do apego.

O apego é um tema freqüentemente estudado por psicólogos que buscam compreender a importância do vínculo inicial da criança como fator de desenvolvimento saudável e preventivo para diversos problemas de comportamento, como ansiedade de separação, desordens de conduta, entre outros (Gomide, 2003; Malagris \& Castro, 2000). No entanto, uma questão que permanece em aberto é como esse vínculo forma-se em crianças institucionalizadas que, não tendo figuras de apego disponíveis, o desenvolvem com seus pais adotivos ou com outras crianças, de forma tardia e sem prejuízos (resiliência). Outra questão que ainda não encontrou resposta no meio científico envolvendo o apego é como essa forma de vinculação na infância age sobre os relacionamentos afetivos no adulto, sendo este mais um campo para futuras pesquisas.

Por fim, o campo de estudo da etologia permite-nos compreender melhor muitos aspectos do comportamento humano. É somente desvelando a evolução humana e voltando-nos para nossos parentes primatas que podemos ter uma pequena idéia de todos os fatores que nos trouxeram até aqui, e assim deliciarmo-nos com a incrível magia de sermos o que somos, com tantas possibilidades que poderiam ter nos levado para outros caminhos.

\section{Referências}

Alcock, J. (2003). A textbook history of animal behaviour. Animal Behaviour, 65, 3-10.

Altmann, S. A. \& Altmann, J. (2003). The transformation of behaviour field studies. Animal Behaviour, 65, 413-423.

Bateson, P. (2003). The promise of behavioural biology. Animal Behaviour, 65, 11-17.

Bear, M. F., Connors, B. W. \& Paradiso, M. A. (2002). Neurociências: desvendando o sistema nervoso. Porto Alegre: Artes Médicas.

Bjorklund, D. F. \& Pellegrini, A. D. (2002). The origens of buman nature. Washington: American Psychological Association.

Blurton Jones, N. (1981). Características do estudo etológico do comportamento humano. Em N. Blurton 
Jones. Estudos etológicos do comportamento da criança. (pp. 3-33). São Paulo: Pioneira.

Bowlby, J. (1990). Apego: a naturez̧a do vínculo. São Paulo: Martins Fontes.

Bussab, V. S. R. (2000). A família humana vista da perspectiva etológica: natureza ou cultura? Interação, 4, 9-22.

Bussab, V. S. R. \& Otta, E. (1992). Desenvolvimento humano: a perspectiva da etologia. Documento CRP08, 2(3), 128-136.

Bussab, V. S. R. \& Ribeiro, F. L. (1998). Biologicamente cultural. Em L. Souza; M. F. Q. Freitas, M. M. P. Rodrigues (Orgs.). Psicologia: reflexões (im)pertinentes. (pp. 175-193). São Paulo: Casa do Psicólogo.

Carvalho, A. M. A. (1989). O lugar do biológico na psicologia: o ponto de vista da etologia. Biotemas, 2(2), 81-92.

Cunningham, E. J. A., Birkhead, T. R. (1998). Sex roles and sexual selection. Animal Behaviour, 56, 1311-1321.

Darwin, C. (2000). A origem das espécies e a seleção natural. São Paulo: Hemus.

Eibl-Eibesfeldt, I. (1989). Human Ethology. New York: Aldine de Gruyter.

Fonseca, V. (1998). Psicomotricidade: filogênese, ontogênese e retrogênese. Porto Alegre: Artes Médicas.

Gomide, P. I. C. (2003). Estilos parentais e comportamento anti-social. Em A. Del Prette e Z. Del Prette (Org.). Habilidades sociais, desenvolvimento e aprendiragem: questões conceituais, avaliação e intervenção. (pp. 21-60). Campinas: Alinea.

Gross, J. (2002). A study of young adult dating couples: gender, childhood parenting, adult attachment style, partner choice, and relationship satisfaction. Journal of Youth and Adolescence, 63(1), 588.

Harlow, H. F. (1959). Love in infant monkeys. Scientific American, 200, 68-74.

Hrdy, S. (2001). Mãe natureza. Rio de Janeiro: Campus.

Krebs, J. R. \& Davies, N. B. (1996). Introdução à ecologia comportamental. São Paulo: Atheneu.
Leakey, R. (1997). A origem da espécie bumana. Rio de Janeiro: Rocco.

Lewin, R. (1999). Evolução humana. São Paulo: Atheneu.

Malagris, L. E. N. \& Castro, M. A. (2000). Distúrbios emocionais e elevação de stress em crianças. Em M. E. N. Lipp (Org.). Crianças estressadas: causas, sintomas e soluçōes. (pp. 65-100). Campinas: Papirus.

Manning, A. (1977). Introdução ao comportamento animal. Rio de Janeiro: Livros Técnicos e Científicos.

Miller, G. F. (2001). A mente seletiva. Rio de Janeiro: Campus.

Rodrigues, M. M. P. (1998). Evolução do investimento parental em primatas: o caso do Homo sapiens. Em L. Souza, M. F. Q. Freitas \& M. M. P. Rodrigues (Orgs.). Psicologia: reflexões (im)pertinentes. (pp. 273-292). São Paulo: Casa do Psicólogo.

Rodrígues-Gironés, M. A. \& Enquist, M. (2001). The evolution of female sexuality. AnimalBehaviour, 61, 695-704.

Sanvito, W. L. (1991). Cérebro e suas vertentes. São Paulo: Roco.

Shettleworth, S. J. (2001). Animal cognition and animal behaviour. Animal Behaviour, 61, 277-286.

Silk, J. B. (1999). Why are infants so attractive to others? The form and function of infant handling in bonnet macaques. Animal Behaviour, 57, 1021-1032.

Small, M. F. (1999). Our babies, ourselves. New York: Anchor Books.

Stringer, C. (2003). Human evolution: out of Ethiopia. Nature, 423, 692-695.

Tinbergen, N. (1951). The study of instinct. New York: Oxford University Press.

Weber, L. N. D. (no prelo). A evolução das relações parentais: uma abordagem etológica. Psicologia Argumento.

West, M. J., King, A. P. \& White, D. J. (2003). The case of developmental ecology. Animal Behaviour, 66, 617-622.

Recebido em janeiro de 2004

Reformulado em maio de 2004

Aprovado em junho de 2004

Sobre os autores:

Plínio Marco De Toni é psicólogo, mestre em Psicologia da Infância e da Adolescência pela Universidade Federal do Paraná e professor adjunto da Universidade Tuiuti do Paraná.

Caroline Guisantes De Salvo é bacharel em Psicologia pela Universidade Federal do Paraná.

Marcos César Marins é psicólogo e mestrando em Psicologia da Infância e da Adolescência pela Universidade Federal do Paraná.

Lidia Natalia Dobrianskyj Weber é mestre e doutora em Psicologia Experimental pela USP, professora do Departamento de Psicologia e do Mestrado em Psicologia da Infância e da Adolescência da Universidade Federal do Paraná. 